\title{
Agrupamento em amostras de sementes de espécies florestais nativas do Estado do Rio Grande do Sul - Brasil
}

\author{
Cluster in seeds samples of native forest species from the State of Rio Grande do Sul - Brazil
}

\author{
Fabiano de Oliveira Fortes ${ }^{\mathrm{I}}$ Alessandro Dal'Col Lúcio ${ }^{\mathrm{I}}{ }^{*}$ Sidinei José Lopes ${ }^{\mathrm{II}}$ \\ Ricardo Howes Carpes ${ }^{\mathrm{III}}$ Bruna Denardim da Silveira ${ }^{\mathrm{I}}$
}

\section{RESUMO}

Este trabalho teve como objetivos agrupar por espécie as matrizes de porta-sementes mais similares, utilizando as variáveis observadas em análises de sementes de espécies florestais nativas no Centro de Pesquisas Florestais e Conservação do Solo, Santa Maria, Rio Grande do Sul, analisadas a partir de 1997 até março de 2001. Para a análise de agrupamento, foram utilizadas todas as espécies que possuíam quatro ou mais análises de amostras de sementes por lote coletado, pelo método de agrupamento aglomerativo hierárquico tendo a distância euclidiana média padronizada como medida de similaridade. O dendograma foi construído utilizando o método da ligação completa. Utilizou-se também a técnica de componentes principais para a redução do número de variáveis. O gênero Schinus sp. e as espécies nativas Cassia leptophylla Vogel, Peltophorum dubium (Spreng.) Taub., Cedrela fissilis Vell., Allophylus edulis (A. St.-Hil., Cambess. \& A. Juss.) Radlk., Lafoensia pacari A. St.-Hil., Enterolobium contortisiliquum (Vell.) Morong. e Apuleia leiocarpa (Vogel) J. F. Macbr. foram as espécies em que, no terceiro e quarto componentes principais, conseguiram explicar aproximadamente $80 \%$ da variação existente no conjunto de dados com a umidade e a percentagem de germinação de plântulas anormais, sendo eliminadas na maioria das espécies e as percentagem de germinação de plântulas normais e de sementes mortas presentes em todos os grupos. A análise de agrupamento mostrou-se eficiente na separação dos grupos de todas as espécies testadas sendo que a procedencia pouco influenciou na formação dos grupos.

Palavras-chave: Distância euclidiana, componentes principais, análise de agrupamento.

\section{ABSTRACT}

This research had the objectives of clustering, the most similar seeds matrixes by species, using the observed variables in analysis of seed samples of native forest species in the Center of Forest Researches and Conservation of the Soil, Santa Maria, Rio Grande do Sul, since 1997 up to March 2001. For the cluster analysis, all the species with four or more seed analysis by analyzed in collected lot, by the hierarchical complete method of the standardized euclidian medium distance as measured of similarity. The dendogram was constructed using the method of complete linkage. The technique of principal components for the reduction of the number of variables was also used. The gender Schinus sp. and the native species Cassia leptophylla Vogel., Peltophorum dubium (Spreng.) Taub., Cedrela fissilis Vell., Allophylus edulis (A. St.-Hil., Cambess. \& A. Juss.) Radlk., Lafoensia pacari A. St. Hil., Enterolobium contortisiliquum (Vell.) Morong. e Apuleia leiocarpa (Vogel) J. F. Macbr., were the species in which the third and fourth principal components explained $80 \%$ the existent variation of the data with the humidity and percentage of abnormal germination seedlings eliminated in the majority species and the percentage of normal germination seedlings and dead seeds found in all the groups. The cluster analysis was efficient in the separation of the groups of all the tested species and origin influenced a little in the formation.

Key words: Euclidian distance, principal components, cluster analysis.

\section{INTRODUÇÃO}

A produção de sementes de alta qualidade requer conhecimento e tecnologia (DELOUCHE, 2002). A qualidade fisiológica de sementes é normalmente obtida pela percentagem de plantas normais em testes

\footnotetext{
IPrograma de Pós-graduação em Engenharia Florestal, Centro de Ciências Rurais (CCR), Universidade Federal de Santa Maria (UFSM), Santa Maria, RS, Brasil.

IIDepartamento de Fitotecnia, CCR, UFSM, 97105-900, Santa Maria, RS, Brasil. E-mail: adlucio@smail.ufsm.br. *Autor para correspondência.

IIIPrograma de Pós-graduação em Agronomia, CCR, UFSM, Santa Maria, RS, Brasil.
} 
de germinação, representando o máximo que a amostra pode oferecer (MACHADO, 2002), uma vez que os testes são conduzidos em condições ótimas, artificiais e padronizadas para cada espécie analisada.

De acordo com as Regras para Análise de Sementes - RAS (BRASIL, 1992), os resultados dos testes de germinação são classificados em: 1) plântulas normais, apresentando-se intactas, com pequenos defeitos e infecção secundária, ainda são consideradas com potencial para continuar seu desenvolvimento e dar origem a plantas normais; 2) plântulas anormais são aquelas que não mostram potencial para continuar seu desenvolvimento e dar origem a plantas normais, por estarem danificadas, deformadas e ou deterioradas; 3) sementes firmes ou duras são as que permanecem sem absorver água por um período mais longo que o normal e se apresentam, portanto, no final do teste com aspecto de sementes recém-colocadas no substrato e 4) sementes mortas são as que no final do teste não germinaram, não estão duras, nem dormentes, e geralmente apresentam-se amolecidas e atacadas por microorganismos. Embora existam outras categorias de sementes não germinadas, na prática, elas são separadas em normal, anormal, firmes e mortas.

Outros quesitos da qualidade de sementes, como a percentagem de pureza, peso de mil sementes e a percentagem de umidade, são avaliados em análise de sementes de espécies florestais e possuem grande variabilidade nas respostas obtidas quando se avaliam diferentes espécies e, dentro de uma mesma espécie, se avaliam a procedência das sementes, o seu lote e o tempo de armazenamento em câmaras frias. Assim, é necessário conhecimento sobre a interferência dessas variáveis na qualidade das sementes armazenadas e o seu potencial de produção de mudas vigorosas.

A estatística experimental é considerada como a principal ferramenta para análise de dados e tem por princípio a consolidação de técnicas adequadas aos diferentes tipos de experimentos. No entatnto não se podem obter boas decisões estatísticas sem boas informações experimentais. Para tanto, os dados precisam ser coletados e interpretados corretamente, pois, segundo GUEDES (2002), o controle estatístico do processo é um método preventivo de se comparar, continuamente, os resultados de um processo sendo o objetivo principal reduzir cada vez mais a variabilidade existente no conjunto de observações.

Entre os métodos fundamentados em modelos biométricos que se destinam à avaliação da diversidade dos progenitores, CRUZ \& REGAZZI (1997) citam vários métodos multivariados que podem ser aplicados, como a análise de componentes principais por variáveis e os métodos aglomerativos. A técnica classificatória multivariada da análise de agrupamento pode ser utilizada quando se deseja explorar as similaridades entre indivíduos ou entre variáveis (LANDIM, 2003). Assim, a análise de agrupamento é o nome dado para as técnicas multivariadas que têm por objetivo fazer grupos baseados em características de similaridade ou dissimilaridade entre observações (CRUZ \& REGAZZI, 1997; JOHNSON \& WICHERNS, 1998; HAIR et al.,1998). A finalidade desta técnica de análise de dados é reunir, por algum critério de classificação, qualquer tipo de unidade amostral em vários grupos, de tal forma que exista homogeneidade dentro do grupo e heterogeneidade entre grupos.

$\mathrm{Na}$ análise de componentes principais, embora $p$ componentes sejam necessários para reproduzir a variabilidade total existente, JOHNSON \& WICHERNS (1998) mostram que algumas vezes explicase a variação com um número reduzido de $\mathrm{k}$ componentes principais. Isso acontece quando são eliminadas as variáveis que pouco contribuem na variação, ficando somente as que realmente contribuem para a variação total, a fim de reduzir a dimensionalidade dos dados, obter combinações interpretáveis das variáveis e descrever e entender sobre a estrutura de correlação das variáveis (BARROSO \& ARTES, 2003).

Assim, o objetivo deste trabalho consiste em agrupar, por espécie, as matrizes de porta-sementes mais similares, utilizando as variáveis observadas em análises de amostras de sementes de espécies florestais nativas do Estado do Rio Grande do Sul, com a redução de variáveis na aplicação dos componentes principais, identificando as variáveis que representam a maior parte da variabilidade existente.

\section{MATERIAL E MÉTODOS}

Foi utilizado o banco de dados de sementes florestais nativas analisadas a partir de 1997 até março de 2001, no Centro de Pesquisas Florestais e Conservação do Solo da Fundação Estadual de Pesquisas Agropecuária, em Santa Maria, Rio Grande do Sul. Os fatores e as variáveis coletadas no banco de dados foram: espécie, procedência, código de identificação do lote coletado, data da coleta do lote, data da análise da amostra de sementes, análise de pureza (\%), peso de mil sementes (PMS) em gramas, umidade (\%), germinação (\%) de plântulas normais (PN), germinação (\%) de plântulas anormais (PA), percentagem de sementes firmes (SF) e percentagem de sementes mortas (SM).

Foram descartadas as espécies que apresentaram um número de análises de sementes iguais ou inferiores a três por lote coletado, para maior precisão 
estatística nos resultados. Primeiramente foi realizada uma análise de componentes principais, sendo aplicado o critério de escolher os componentes que explicavam aproximadamente $80 \%$ das variações existentes e, após este passo, eliminar as variáveis que apresentavam menor contribuição nos primeiros componentes e maior nos últimos.

Com as variáveis selecionadas, realizou-se a análise de agrupamento pelo Método Hierárquico Aglomerativo para cada espécie, no qual, num primeiro passo, a matriz de parecença foi utilizada para identificar o par de objetos que mais se parecem. Depois disso, esse par foi agrupado e considerado como sendo um único objeto, redefinindo-se nova matriz de parecença e, em seguida, identificando-se o par mais semelhante, que formará um novo grupo, e assim, sucessivamente, até que todos os objetos estivessem reunidos num mesmo grupo. Pelo método do vizinho mais distante (ligação completa), definiu-se a distância como sendo a maior entre um elemento de $\mathrm{d} 1$ e um elemento de $\mathrm{d} 2$ por meio da distância Euclidiana. A escolha desse método foi devido ao fato deste fornecer grupos mais homogêneos, favorecendo a discussão e a interpretação dos resultados obtidos. Para contornar o problema de escalas e medidas das variáveis, foram utilizados dados padronizados e, para contornar a influência do número de variáveis, utilizou-se a distância Euclidiana média, descrita por CRUZ \& REGAZZI (1994). Para cada espécie, dentro dos grupos foi calculada a média aritmética, para caracterização dos grupos.

Foi utilizado o software estatístico SAEG, versão 9.0, aplicando o teste t a 5\% probabilidade de erro, para comparação de médias entre grupos, quando este possuía mais de uma amostra.

\section{RESULTADOS E DISCUSSÕES}

Após a análise de componentes principais, observou-se que as variáveis percentagem de plântulas normais (PN) e percentagem de sementes mortas (SM) estiveram presentes em todas as espécies, sendo que na Lafoensia pacari a PN chegou a contribuir com 64,0\%, enquanto que na espécie Apuleia leiocarpa a SM contribuiu com $41,2 \%$. A variável que menos se fez presente foi a percentagem de plântulas anormais (PA), contribuindo com $11,8 \%$ somente na Peltophorum dubium. A umidade esteve presente em três espécies, a pureza em quatro e o peso de mil sementes (PMS) e a percentagem de sementes firmes (SF) em cinco (Tabela 1 ).

Na figura 1A, para o gênero Schinus sp., verifica-se que, após o agrupamento, foram selecionados três grupos, sendo que o primeiro, com três análises, destacou-se pela formação mais homogênea, perto dos $40 \%$. Já o segundo foi composto por apenas uma análise, que uniu-se ao grupo I somente perto dos $85 \%$, por isso ficou isolado.Por fim o terceiro,

Tabela 1 - Percentagem de contribuições das variáveis: pureza (\%), peso de mil sementes (PMS), umidade (\%), percentagem de germinação de plântulas normais (PN), percentagem de germinação de plântulas anormais (PA), percentagem de sementes firmes (SF), percentagem de sementes mortas (SM) pela análise de componentes principais, para sementes de diferentes espécies florestais nativas do Estado do Rio Grande do Sul. Santa Maria, RS - 2007.

\begin{tabular}{|c|c|c|c|c|}
\hline Variáveis & Schinus sp. & Cassia leptophylla & Peltophorum dubium & Cedrela fissilis \\
\hline Pureza & 9,2 & -- & -- & 21,6 \\
\hline PMS & 15,8 & 17,6 & -- & 13,1 \\
\hline Umidade & 29,2 & 24,5 & -- & -- \\
\hline $\mathrm{PN}$ & 21,6 & 28,6 & 46,3 & 42,6 \\
\hline SF & 2,5 & -- & 10,3 & -- \\
\hline PA & -- & -- & 11,8 & -- \\
\hline SM & 21,6 & 26,4 & 31,6 & 22,6 \\
\hline TOTAL & 100,0 & 100,0 & 100,0 & 100,0 \\
\hline Variáveis & Allophylus edulis & Lafoensi pacari & Enterolobium contortisiliquum & Apuleia leiocarpa \\
\hline Pureza & 24,2 & 14,7 & -- & -- \\
\hline PMS & 10,6 & -- & -- & 16,2 \\
\hline Umidade & -- & -- & 25,8 & -- \\
\hline $\mathrm{PN}$ & 39,4 & 63,97 & 32,6 & 33,8 \\
\hline $\mathrm{SF}$ & 15,1 & -- & 11,0 & 8,8 \\
\hline $\mathrm{PA}$ & -- & -- & -- & -- \\
\hline SM & 10,6 & 21,32 & 30,5 & 41,2 \\
\hline TOTAL & 100,0 & 100,0 & 100,0 & 100,0 \\
\hline
\end{tabular}

Ciência Rural, v.38, n.6, set, 2008. 


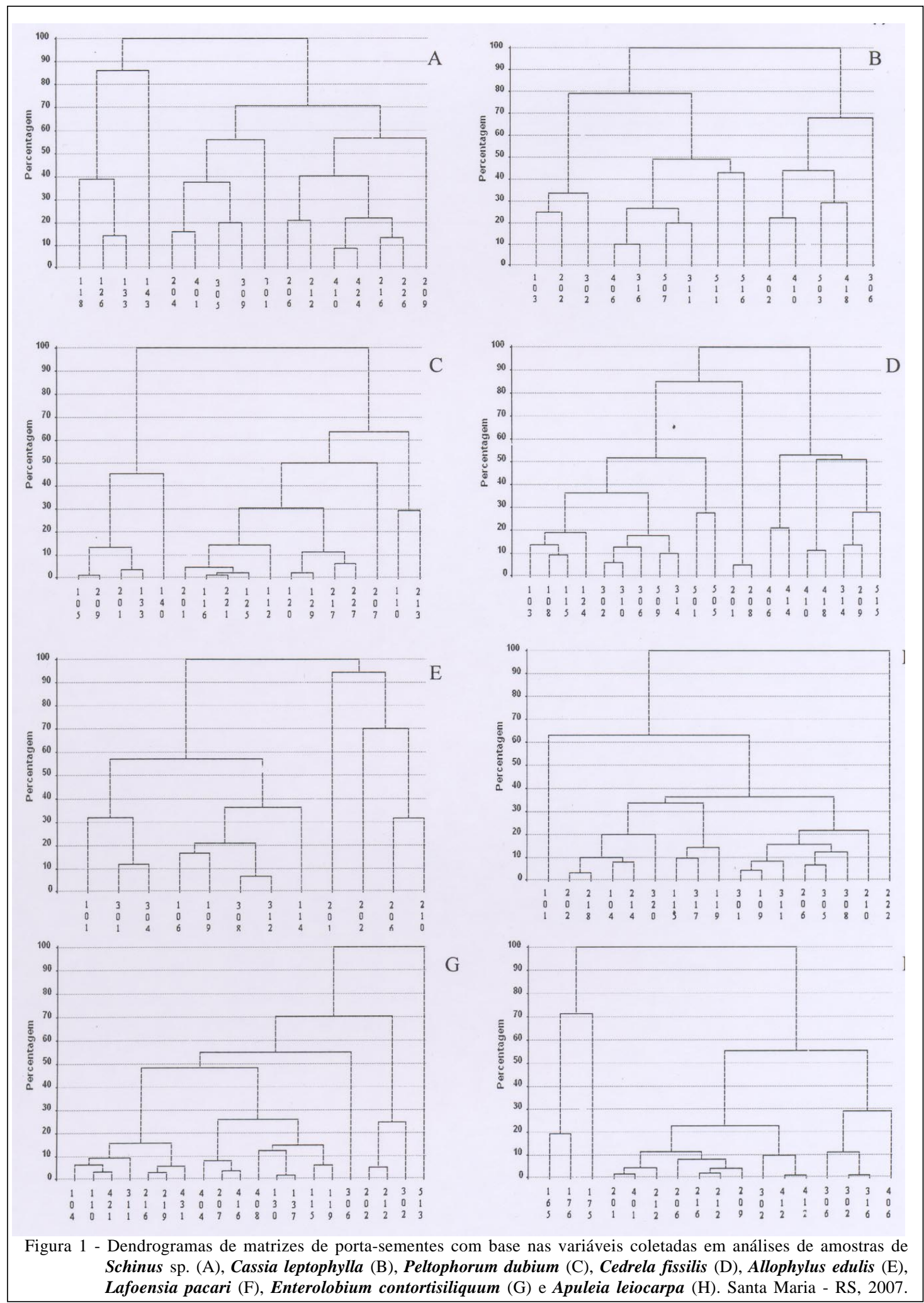

composto por 12 análises, nas quais perto dos 70\% agruparam-se para a formação do grupo. Na análise de componentes principais, a contribuição das SM foi de
21,7\%, assim como a PN, já a umidade foi a variável com maior contribuição (29,2\%) e a de menor amplitude entre valores, mostrando que nesse gênero a variação

Ciência Rural, v.38, n.6, set, 2008. 
não está diretamente relacionada às contribuições, porém não se deve desconsiderar que os resultados encontrados para o gênero Schinus sp. levam provavelmente a variações pertinentes de espécies diferentes. As diferenças entre as médias do grupo I e
III das variáveis pureza e umidade mostraram-se não significativas (Tabela 2).

Já o PMS mostrou diferença significativa, sendo que o grupo III $(19,94 \mathrm{~g})$, que corresponde à metade do I, com 42,41g, e o grupo II, com 43,05g,

Tabela 2 - Valores médios e número de observações (N), procedência, pureza (\%), peso de mil sementes (PMS) em gramas, umidade (\%), percentagem de germinação de plântulas normais (PN), percentagem de germinação de plântulas anormais (PA), percentagem de sementes firmes (SF), percentagem de sementes mortas (SM), após a realização da análise de componentes principais, das variáveis observadas em análises de sementes de espécies nativas. Santa Maria - RS, 2007.

\begin{tabular}{|c|c|c|c|c|c|c|c|c|c|}
\hline Grupo & $\mathrm{N}$ & Procedência & Pureza & PMS & Umidade & PN & SF & PA & SM \\
\hline \multicolumn{10}{|c|}{-----------------------------------------------------------Schinus sp. (aroeira) ---------------------------------------------------------- } \\
\hline I & 3 & Veranópolis & 98,9 & 42,4 & 9,9 & 73,7 & 6,3 & - & 19,9 \\
\hline \multirow[t]{2}{*}{ II } & 1 & Veranópolis & 98,9 & 43,0 & 11,0 & 16,0 & 71,5 & - & 12,5 \\
\hline & & Veranópolis & & & & & & & \\
\hline \multirow[t]{2}{*}{ III } & 12 & Santa Maria & 97,3 & 19,9 & 11,4 & 41,8 & 0,2 & - & 58,0 \\
\hline & & Sobradinho & & & & & & & \\
\hline & & & --Cas & & ogel (falsc & & & & \\
\hline I & 3 & Santa Maria & - & 135,0 & 13,5 & 73,8 & - & - & 26,2 \\
\hline II & 6 & $\begin{array}{l}\text { Restinga Seca } \\
\text { Santa Maria }\end{array}$ & - & 141,8 & 10,8 & 66,3 & - & - & 32,6 \\
\hline III & 5 & $\begin{array}{c}\text { Santa Maria } \\
\text { Restinga Seca }\end{array}$ & - & 135,1 & 11,6 & 41,5 & - & - & 57,9 \\
\hline \multirow[b]{2}{*}{ I } & & E.E.S. & & & & & & & \\
\hline & 5 & Santa Maria & - & - & - & 73,2 & 0,0 & 0,0 & 26,8 \\
\hline II & 12 & $\begin{array}{c}\text { E.E.S. } \\
\text { Santa Maria }\end{array}$ & - & - & - & 88,7 & 0,3 & 0,4 & 10,6 \\
\hline & & & $---C e d r$ & issilis $\mathrm{V}$ & (cedro) --- & & ---- & 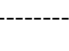 & --- \\
\hline I & 11 & $\begin{array}{l}\text { Independência } \\
\text { S. do Livramento }\end{array}$ & 89,0 & 32,1 & - & 90,9 & - & - & 8,4 \\
\hline II & 2 & Passo Fundo & 92,2 & 21,1 & - & 93,0 & - & - & 5,2 \\
\hline III & 7 & $\begin{array}{l}\text { Sobradinho } \\
\text { S. do Livramento }\end{array}$ & 76,2 & 28,9 & - & 76,7 & - & - & 23,1 \\
\hline I & 8 & $\begin{array}{l}\text { São José } \\
\text { E.E.S. }\end{array}$ & 98,8 & 32,1 & 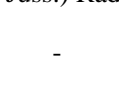 & 51,5 & 3,0 & 0,0 & 45,5 \\
\hline II & 1 & Veranópolis & 97,1 & 43,3 & - & 0,0 & 96,7 & 0,0 & 3,2 \\
\hline III & 1 & Veranópolis & 96,7 & 45,6 & - & 0,0 & 0,0 & 97,0 & 3,0 \\
\hline IV & 2 & Veranópolis & 97,2 & 46,0 & - & 0,0 & 0,0 & 0,0 & 96,0 \\
\hline I & 16 & E.E.S. & $\begin{array}{c}\text { afoensia } \\
91,4\end{array}$ & $\begin{array}{l}\text { ri A. St } \\
-\end{array}$ & l. (dedaleir & 75,5 & - & - & 21,0 \\
\hline \multirow[t]{2}{*}{ II } & 1 & E.E.S. & 97,2 & - & - & 9,0 & - & - & 91,0 \\
\hline & & ------Enterol & Im conto & iquum & 1.) Morong & nbaúva & ------ & ----- & ---- \\
\hline I & 19 & $\begin{array}{c}\text { General Câmara } \\
\text { Santa Maria }\end{array}$ & - & - & 9,2 & 94,4 & 0,0 & - & 5,4 \\
\hline II & 1 & $\begin{array}{l}\text { São Borja } \\
\text { Formigueiro }\end{array}$ & - & - & 7,6 & 82,5 & 0,5 & - & 17,0 \\
\hline I & 3 & $\begin{array}{c}\text { Porto Alves } \\
\text { Restinga Seca }\end{array}$ & - & 80,3 & - & 22,8 & 0,7 & - & 76,5 \\
\hline II & 14 & $\begin{array}{l}\text { Porto Alves } \\
\text { Valfeltrina }\end{array}$ & - & 96,5 & - & 80,4 & 0,0 & - & 19,6 \\
\hline
\end{tabular}

E.E.S. Estação Experimental Santa Maria. 
mostraram que os grupos I e II são próximos quanto ao PMS. As PN nas quais o grupo I teve $73,7 \%$ e os grupos II e III tiveram 16\% e 41,8\%, respectivamente, mostraram diferença significativa, assim como as SM pelo teste $\mathrm{t}$ entre os grupos I e III. No grupo I, é notada a superioridade quanto à PN. Tal característica é devida a um dos lotes, de Veranópolis, que ficou armazenado por três anos e meio sem perder o vigor, embora na primeira análise desta a percentagem de germinação tenha sido baixa, devido provavelmente à umidade mais alta. O grupo II, em decorrência do tempo de armazenamento, perdeu o poder germinativo, sendo que apenas $16 \%$ foram normais e $71,5 \%$ firmes, mostrando que este perdeu o vigor. Observa-se que neste grupo II não se fez comparação de média porque havia somente uma análise de sementes de um único lote neste grupo. O gênero Schinus sp. sofreu interferência da localidade de coleta, visto que as sementes provenientes da cidade de Veranópolis são superiores às demais.

Houve formação de três grupos para Cassia leptophylla Vog. (Figura 1B), sendo que o primeiro agrupou-se perto dos 35\%, com três análises, o segundo grupo com seis análises uniu-se nos 50\% e o terceiro próximo aos $69 \%$, com cinco análises. O método dos componentes principais mostrou-se eficiente, sendo que, no terceiro agrupamento, representa $80,6 \%$ da variação total da espécie e nos grupos I, II e III, contribuíram principalmente com as variáveis PN e SM. A média da germinação normal do grupo I: 73,8\% e do grupo II: $66,3 \%$ não foram significativas, porém, estas foram superiores ao grupo III e ambas foram significavas quando comparadas com este grupo, que apresentou $41,5 \%$ de germinação normal (Tabela 2). As SM do grupo I (26,2\%) é menor que as do grupo II (32,6\%), porém, não significativo. Já o terceiro grupo, que apresentou um valor bem mais alto, 57,9\% de SM, foi significativo com mesmo erro, mostrando que os grupos I e II são melhores quanto a estas variáveis. Dois lotes (47/01 e 53/00), de Restinga Seca (pertencentes ao grupo III), poderiam ser excluídos do estoque de sementes por estarem abaixo dos 50\% de germinação normal na primeira avaliação. Um lote (26/99), de Santa Maria, pertencente ao primeiro grupo, em um ano e meio começou a perder o vigor e sua percentagem de germinação foi para $60 \%$ na terceira avaliação. Este último é marcado pela irregularidade, pois, na segunda análise, o mesmo teve pouca germinação normal e alta mortalidade, agrupando-se no segundo grupo. Lotes de General Câmara e Santa Maria tiveram apenas uma análise pertencente ao primeiro grupo.

Na espécie Peltophorum dubium (Spreng.)

Taub, foram encontrados dois grupos (Figura 1C), sendo que o primeiro é composto por cinco análises e o segundo de 12 . Destaca-se que o primeiro uniu-se próximo aos $45 \%$ e o segundo aos $64 \%$, para agrupar todas as análises. Quanto às contribuições (Tabela 1), a PN teve $46,3 \%$ e as SM 31,6\%, explicando aproximadamente $77 \%$ do agrupamento e revelando sua importância para a formação dos grupos. Já as SF e a PA, com 10,3 e 11,8\%, respectivamente, também contribuíram, porém, com menor percentagem. Na terceira formação dos componentes principais, 79\% da variação existente das sementes de Peltophorum dubium estavam sendo explicadas na formação dos grupos. O primeiro grupo, formado por canafístula (Tabela 2), teve, em média, 73,2\% de germinação normal e $26,8 \%$ de mortas, já o grupo II apresentou $88,7 \%$ e $10,6 \%$, respectivamente, indicando uma superioridade desse grupo em relação ao primeiro e apresentando em ambas as variáveis diferenças significativas. O lote 21/ 99, de Santa Maria, na primeira análise, revelou uma baixa PN, na faixa dos 70\%, embora em outras análises tenha apresentado uma boa germinação, próxima aos 90\%. O lote 30/98, da estação experimental de Santa Maria, é melhor que o primeiro, com uma germinação que atinge os $90 \%$ após um ano e meio de armazenamento e que diminuiu somente com dois anos e meio, o que demonstra uma alta resistência póscolheita no armazenamento desta espécie.

Para a Cedrela fissilis Vell., formou-se o primeiro grupo próximo aos 52\%, com 11 análises, sendo este o maior e mais homogêneo dos grupos encontrados. Já o segundo foi composto por duas análises, formando perto dos 5\%, e o terceiro uniu-se nos 53\%, com sete análises de sementes. Nas contribuições, a variável que mais influenciou foi a PN, a qual explicou 42,6\%, seguida da pureza com 21,6\%, das sementes mortas com 22,6\% e do PMS com 13,1\% (Tabela 1). A contribuição da germinação normal expressa quase a metade das explicações dos grupos, demonstrando sua importância para a formação dos mesmos.

A análise de componentes principais mostrou-se eficiente, explicando, até o terceiro componente, $77 \%$ da variação existente nas sementes de Cedrela fissilis. Na análise de agrupamento, fez-se a separação em três grupos. O primeiro grupo com a pureza em $89,0 \%$, mostrou-se melhor que o grupo III, o qual ficou com $76,2 \%$, mas o grupo que mais se destacou foi o II, que obteve $92,2 \%$ de pureza (Tabela 2), porém, este não mostrando diferença significativa em relação ao primeiro. Já o grupo III mostrou-se significativamente diferente em relação ao primeiro e ao segundo grupo. O PMS do grupo III é 28,94g, valor menor que o grupo I, de 32,34g, e ambos maiores que o grupo II $(21,13 \mathrm{~g})$, sendo todos significativamente diferentes. As PN apresentaram 90,9\% no grupo I, 93,0\% no II, e 76,7\% 
no III, indicando que o primeiro e o segundo são melhores e têm diferenças significativas quando comparadas com o grupo III. Já os grupos I e II não apresentaram estas diferenças. As SM do primeiro grupo ficaram com $8,4 \%$, e as do segundo com $5,2 \%$, mostrando-se bastante inferiores às do terceiro grupo, com $23,1 \%$, indicando que os lotes do primeiro e do segundo grupos são melhores e apresentaram diferenças significativas quando comparados com o terceiro grupo, já os grupos I e II não apresentaram diferenças significativas. O lote 93/99, de Independência, é de qualidade inferior quando comparado com os demais lotes, pois este somente na primeira análise esteve acima da média geral quanto à PN, assim como o lote 60/98, da mesma localidade, o qual em seis meses começou a cair seu poder germinativo. Pertencentes ao segundo grupo, o lote 43/97, de Sobradinho, ficou dois anos guardados e teve quatro análises nesse espaço de tempo sem diminuir sua PN. Já os lotes 70/00, de Livramento, e 35/99, de Santana do Livramento, ficaram guardados aproximadamente um ano e germinaram $90 \%$, mostrando que devem ser mantidas as análises desses lotes para se saber o tempo máximo de armazenamento dos mesmos.

Foram selecionados quatro grupos para a espécie Allophylus edulis (A. St.-Hil., Cambess. \& A. Juss.) Radlk. (Figura 1E) sendo que o primeiro com oito análises, destaca-se pela formação mais homogênea e pelo maior número de análises, no qual perto dos 58\% houve o agrupamento. Quanto aos demais, são pertencentes todos ao mesmo lote, mudando somente o tempo de armazenamento, sendo que o segundo e o terceiro são compostos somente por uma análise, agrupando-se nos $95 \%$ e nos $70 \%$ respectivamente, e o terceiro é composto por duas análises, ocorrendo a ligação próxima aos $32 \%$ para a formação do grupo. A análise de componentes principais mostrou-se eficiente, explicando na terceira formação $86 \%$ da variação existente nas sementes de chal-chal, sendo a pureza $(24,2 \%)$ e a PN $(39,4 \%)$ as variáveis que mais contribuíram.

O grupo I foi o que demonstrou os melhores resultados, com uma PN de 51,5\%, sendo que os grupos II e III zeraram esta variável e o IV teve $4 \%$ de PN. Para o chal-chal (Tabela 2), o grupo II diferencia-se do I pelo fato de ter $0 \%$ de germinação normal e $96,7 \%$ de firmes, maior valor encontrado entre as espécies das SF. O grupo III diferencia-se do I por ter $0 \%$ de PN e do II por ter $97 \%$ das anormais, sendo este o valor máximo da PA entre as espécies. Neste grupo, aqueles que não eram anormais estavam mortos. O grupo IV, com duas análises, distinguiu-se dos outros pela germinação das mortas, que chegou a $96 \%$, sendo que apenas $4 \%$ das sementes conseguiram germinar. Este grupo apresentou diferença significativa, quando comparada com o grupo I. Pelo dendrograma da figura $1 \mathrm{E}$, constatou-se que os grupos III e IV unem-se nos $70 \%$. De acordo com a metodologia aplicada, até essa percentagem estaria em um mesmo grupo, porém, como nesta espécie a diferença entre estes grupos era muito grande (Tabela 2), optou-se por sua separação. O lote 94/96, de Veranópolis, é o formador dos grupos II, III e IV, estando há aproximadamente sete anos armazenado e isso deve ser a causa de seu mau desempenho quanto à PN e das altas taxas de anormais, firmes e mortas. Os lotes pertencentes ao grupo I (99/97 e 111/98), de São José e da estação experimental de Santa Maria, respectivamente, em menos de um ano, começaram a perder o potencial de germinação e ficaram na faixa dos $50 \%$, sendo que a partir deste tempo, esta espécie tem uma pequena vida útil na câmara fria.

Para a Lafoensia pacari A. St.-Hil. (Figura $1 \mathrm{~F}$ ), houve a formação de dois grupos, sendo o primeiro formado por 16 análises, encontrando-se próximas dos 63\% pela ligação completa da distância média euclidiana padronizada. O grupo II foi formado apenas pela matriz 16 e liga-se com o grupo I somente nos $100 \%$, de acordo com o dendrograma. Na média dentro dos grupos (Tabela 2), a pureza no grupo I, com $91,4 \%$, foi menor que no grupo II, no qual esta variável com 97,2\% obteve melhor desempenho quanto à pureza encontrada, porém, esta variável é alta em ambos os grupos. Quanto às sementes mortas no primeiro grupo, a média foi de $21,0 \%$, enquanto que no segundo foi de 91,0\%, sendo este valor o máximo da SM encontrada entre as espécies, evidenciando-se a perda do vigor do grupo II. A análise de componentes principais foi eficiente, uma vez que diminuiu de sete para três variáveis, explicando, na terceira formação, $71 \%$ da variação existente nas sementes de dedaleiro. Todas as análises do dedaleiro são da estação experimental de Santa Maria e o lote 22/98, a que pertence o grupo II, só perdeu o poder germinativo depois de um ano e meio, na sexta análise. Nas análises anteriores, o lote teve um bom desempenho, inclusive acima da média do grupo. Os lotes 38/97 e 60/00 também tiveram um bom desempenho dentro de um ano de análise, sendo que após este período começaram a ter o potencial germinativo reduzido.

A formação dos grupos de Enterolobium contortisiliquum (Vell.) Morong. (Figura 1G) deu-se em dois grupos, em que o primeiro é composto por 19 análises unindo-se nos $70 \%$ e o segundo é composto por uma análise, que se agrupou nos $100 \%$, conforme o 
dendrograma. A análise dos componentes principais foi eficiente, com uma redução no número de variáveis de sete para quatro, explicando, na terceira formação, 73\% da variação. Dos grupos em destaque (Tabela 2), o primeiro com 19 análises e o segundo com apenas uma, mostrando que, em alguma análise, o poder germinativo do lote diminui, ficando somente esta análise. Contudo ficou constatado que, na primeira análise do lote 41/98, quanto à SM, este teve um valor alto com 17,0\%, quando comparado ao primeiro grupo, 5,4\%. Com isso, observase que esta análise isolou-se das demais pelo número de mortas. Entretanto, a germinação normal do grupo II, com 82,5\%, não pode ser considerada baixa, porém, é menor que a do primeiro grupo, que teve $94,4 \%$ quanto à percentagem de plântulas germinadas. O lote 41/99, de Santa Maria, está na sexta análise e, em três anos armazenados, ainda não perdeu o vigor de suas sementes, assim como o lote 83/97, de Formigueiro, que está na quinta análise e há quase três anos armazenado e ainda está germinando na faixa dos $90 \%$ normal. Os lotes 81/00, de São Borja, e 64/00, de Santa Maria, estão há mais de um ano e ainda têm um ótimo poder germinativo. Os resultados mostram que a vida útil após o armazenamento das sementes de $\boldsymbol{E}$. contortisiliquum é de aproximadamente três anos, com 90\% de germinação normal, e que tanto as procedentes de Santa Maria como as de Formigueiro são parecidas.

Foi verificada a formação de dois grupos para a Apuleia leiocarpa (Vog.) J. F. Macbr., sendo que o primeiro agrupou-se perto dos $72 \%$, com três análises, e o segundo, maior e mais homogêneo, agrupou-se nos 55\%, com 14 análises (Figura 1H). As variáveis que mais contribuíram para a formação dos daqueles foram as SM com $41,2 \%$, seguidas pela PN, com 33,8\%, o PMS com 16,2\% e, por último, o SF com 8,8\% (Tabela 1). A análise de componentes principais mostrou-se eficiente, explicando-se na segunda formação 88\% da variação existente. O grupo I é inferior e mostrou-se significativamente diferente nas variáveis PMS (80,31g), PN (22,8\%), SF (0,7\%) e SM (76,5\%), quando comparado com o grupo II, bem superior, com PMS (96,5g) e PN (80,4\%), sendo este valor aproximadamente três vezes maior que do primeiro grupo e $19,6 \%$ de SM valor bem menor que o primeiro grupo, mostrando a superioridade do segundo grupo sobre o primeiro. O lote 10/92, de Porto Alves, enquadrou-se no grupo I, quando realizadas as primeiras análises, e estava há aproximadamente cinco anos em armazenamento, por isso seu número de sementes mortas é elevado e deve ser excluído armazenamento. Os lotes 05/00, de Restinga Seca, e 04/ 98, de Valfeltrina, estavam há um ano armazenados quando foram realizadas cinco e quatro análises, respectivamente, e ainda não haviam perdido o vigor. O lote 03/98, de Porto Alves, ficou o mesmo período de um ano em armazenamento e teve o seu potencial germinativo reduzido, indicando que há influência da procedência na qualidade da semente.

\section{CONCLUSÕES}

Após a formação dos componentes principais, a umidade das amostras de sementes e a percentagem de germinação de plântulas anormais (PA) foram as variáveis eliminadas cinco e sete vezes, respectivamente, de oito espécies estudadas. Já a percentagem de germinação de plântulas normais (PN) e a percentagem de sementes mortas (SM) estiveram presentes em todos os grupos, sendo as mais representativas da variabilidade existente nos dados de análises de sementes de espécies florestais nativas.

A técnica de agrupamento mostrou-se eficiente na formação de grupos com as variáveis coletadas nas análises de amostras de sementes, sendo que a procedência pouco influenciou no agrupamento das espécies. Normalmente houve formação de dois e três grupos, na maioria das espécies estudadas, sendo que muitas matrizes tiveram somente uma análise e esta foi diferente dos demais pela percentagem de sementes mortas.

\section{AGRADECIMENTOS}

À Fundação Estadual de Pesquisas Agropecuária/ RS, pelo fornecimento dos dados. Ao Conselho Nacional de Desenvolvimento Científico e Tecnológico (CNPq) e à Coordenação de Aperfeiçoamento de Pessoal de Nível Superior (CAPES), pelo auxílio financeiro e bolsas de iniciação científica e produtividade em pesquisa.

\section{REFERÊNCIAS}

BARROSO, L.P.; ARTES, R. Análise multivariada: minicurso do $10^{\circ}$ Simpósio de Estatística Aplicada a Experimentação Agronômica - RBRAS e 48a Reunião Anual da Região Brasileira da Sociedade Internacional de Biometria - SEAGRO - LavrasMG: UFLA, 2003. 156p.

BRASIL. Ministério da Agricultura e Reforma Agrária. Secretaria Nacional de Defesa Agropecuária. Departamento Nacional de Defesa Vegetal. Regras para análise de sementes. Brasília, 1992. 365p.

CRUZ C.D.; REGAZZI A.J. Modelos biométricos aplicados ao melhoramento genético. Viçosa: UFV/IU, 1997. 390p.

DELOUCHE, J.C. Germinação, deterioração e vigor da semente. Seednews, Pelotas, v.6, n.6, p.24-31, 2002.

Ciência Rural, v.38, n.6, set, 2008. 
GUEDES, T.A. Introdução ao controle da qualidade. Melhoria contínua da qualidade. Maringá: UEM/DES, 2002. 84p.

HAIR J.F. Jr. et al. Multivariate data analysis. 5.ed. New Jersey: Prentice-Hall, 1998. 569p.

JOHNSON, R.A.; WICHERNS, D.W. Applied multivariate statistical analysis. 3.ed. New Jersey: Upper Saddle River, 1998. 642p.
LANDIM, P.M.B. Análise estatística de dados geológicos. 2.ed. São Paulo: Fundação Editora da UNESP/FEU, 2003. 253p.

MACHADO, C.F. Metodologia para a condução do teste de germinação e utilização de raios- $X$ para a avaliação da qualidade de sementes de aroeira-branca (Lithraea molleoides (Vell.) Engl.), 2002. 83p. Dissertação (Mestrado em Agronomia) - Universidade de São Paulo/Escola Superior de Agricultura Luiz de Queirós. Piracicaba. 2002. 